New Drug Update

\title{
Prucalopride: novel drug for chronic idiopathic constipation
}

\author{
Pawan Dhull $^{1}$, Sachin Maggo ${ }^{2 *}$, Piyush Angrish ${ }^{3}$, Anuj Singh ${ }^{4}$, Uthara K. S. ${ }^{2}$, Akhila A. S. ${ }^{5}$
}

${ }^{1}$ Department of Neurology, Government Hospital, Lucknow, Uttar Pradesh, India

${ }^{2}$ Department of Medicine, ${ }^{3}$ Department of Sports Medicine, ${ }^{4}$ Department of Anaesthesia, Joshimath, Uttarakhand, India ${ }^{5}$ Department of Medicine, Government Hospital, Agra, Uttar Pradesh, India

Received: 02 June 2019

Revised: 30 June 2019

Accepted: 09 July 2019

\section{*Correspondence to:}

Dr. Sachin Maggo,

Email: sachinmaggo2003@ gmail.com

Copyright: (C) the author(s), publisher and licensee Medip Academy. This is an openaccess article distributed under the terms of the Creative Commons Attribution NonCommercial License, which permits unrestricted noncommercial use, distribution, and reproduction in any medium, provided the original work is properly cited.

\begin{abstract}
Chronic Idiopathic Constipation (CIC), defined as constipation in which the underlying cause is unknown, is a common medical illness with a profound negative impact on health-related quality of life and increased propensity for life threatening complications. Current treatment for CIC includes lifestyle modifications, over-the-counter medications, and prescription medications. Presently, the only approved, prescription products for CIC in the US are prosecretory agents. However, the current knowledge that serotonin plays an important role in colonic motility has opened new horizons in the treatment of CIC promoting use of prokinetic agents with a different mechanism of action. Prucalopride is a highly selective 5-hydroxytryptamine type 4 (5-HT4) receptor agonist that enhances propulsive motor patterns in the large intestine due to a high affinity for 5-HT4 receptors in gastrointestinal (GI) tissues. The onset of action of Prucalopride is fast, shows rapid absorption, oral bioavailability of $93 \%$ and linear pharmacokinetics. Most common adverse reactions seen are headache, nausea, diarrhea, and abdominal pain. Clinical trials for Prucalopride have been positive, and results suggest that the drug may be a new safe and effective option for CIC treatment, especially for patient's refractory to prosecretory agents. As a prescription drug for the management of constipation and given the virtual demise of other prokinetic agents for this indication, prucalopride competes primarily with another class of agents: those that stimulate secretion. With Shire Pharmaceuticals having already received US FDA approval in Dec 2018, Prucalopride may soon be a new addition to the mounting armoury of drugs against CIC.
\end{abstract}

Keywords: Chronic Idiopathic Constipation, 5 HT4 receptor agonists, Prokinetic agents, Prucalopride

\section{INTRODUCTION}

Chronic Idiopathic Constipation (CIC), defined as constipation in which the underlying cause is unknown (ie, not caused by another disease or a medication), is a common and often enervating medical illness encountered by physicians daily. Several working groups (World Gastroenterology Organization, American
Gastroenterological Association, American College of Gastroenterology, and the Rome Foundation working group) have recognized that the condition comprises multiple symptoms, including straining during defecation, lumpy or hard stools, sensation of incomplete evacuation, and fewer than 3 defecations per week. ${ }^{1}$ (Table 1) Additionally, patients with CIC often feel bloated and have abdominal pain. CIC represents an extremely troublesome disorder with a profound negative impact on health-related 
quality of life as other chronic conditions such as diabetes or heart disease and depression in women. ${ }^{2,3}$ Also, CIC can lead to increased risk for serious complications and has been associated with comorbidities such as faecal impaction, diverticular disease, and rectal prolapse. 4 The prevalence of chronic constipation is $10.0 \%-14.9 \%$ in the USA. ${ }^{5,6}$ An estimated 35 million adults have CIC in the United States (US).6 Chronic idiopathic constipation is more prevalent in women, non-Whites, and elderly patients. Chronic idiopathic constipation is associated with lower socioeconomic status, low fibre diet, and lack of exercise. $^{6-9}$

\section{Table 1: Modified ROME Foundation diagnostic criteria for functional constipation.}

Patients with < 3 SCBMs per week and at least 2 of

the following for at least $25 \%$ of the time, and

symptoms must have occurred at least 6 months

prior to diagnosis and should have been present

during the last 3 months

Straining during defecations

Lumpy or hard stools

Sensation of incomplete evacuation

Sensation of anorectal obstruction/blockage

Manual maneuvers to facilitate defecations (e.g.,

digital evacuation, support of pelvic floor)

SCBM: Spontaneous complete bowel movement

The goal of treatment for CIC is to reinstate normal bowel function, thereby increasing complete spontaneous bowel movement (CSBM) leading to an improvement in healthrelated quality of life. Current treatment for CIC includes lifestyle modifications, over-the-counter medications, and prescription medications. Presently, the only approved, prescription products for CIC in the US are prosecretory agents. In general, prosecretory agents act by enhancing fluid secretion into the GI tract.

Three drugs are currently licensed in the US: lubiprostone, linaclotide, and plecanatide. Tegaserod, a non-selective 5HT4 agonist working by stimulating gut motility via 5HT4 agonism was approved in the US in 2002 for the treatment of IBS-C and CIC but was later voluntarily withdrawn from the US market in 2007 market due to reports of serious cardiovascular ischemic events, unstable angina, heart attack, and stroke.

In spite of available treatment options, there continues to be vast patient discontent with results and an overall unmet need for additional treatment options for CIC, while counting on a different mechanism of action than presently available prosecretory agents. ${ }^{10-11}$

Prucalopride is a highly selective 5-hydroxytryptamine type 4 (5-HT4) receptor agonist developed by Shire Pharmaceuticals that stimulates colonic motility providing substantial symptomatic improvement in patients with CIC. It acts by increasing the number and amplitude of high amplitude propagating contractions (HAPCs), ie, the peristaltic contractions moving the contents of the colon forward as against osmotic laxatives and prosecretory products which use alternative mechanisms of action. The US Food and Drug Administration (FDA) has approved Shire's Prucalopride (Motegrity) in December 2018 for the treatment of CIC. ${ }^{12}$

\section{MECHANISM OF ACTION}

It has been found that serotonin plays important role in colonic motility; hence serotonin receptors have long been targets for research in treatment of CIC. Prucalopride is a dihydro-benzofuran carboxamide derivative approved in October 2009 by the European Medicine Agency for the treatment of Functional constipation (FC) in adults in whom treatment with laxatives failed to provide relief. It is a highly selective 5-hydroxytryptamine type 4 (5-HT4) receptor agonist that effectually enhances propulsive motor patterns in the large intestine due to a high affinity for 5-HT4 receptors in gastrointestinal (GI) tissues. It works by enhancing longitudinal smooth muscle contraction and promoting propulsion of luminal contents while reducing the resistance potentially produced by circular smooth muscle contractions. ${ }^{13,14}$ Moreover, administration of prucalopride induces HAPC, that are grossly decreased or absent in patients with CIC. ${ }^{15,16}$ The drug's affinity for other receptors is present only at concentrations that exceed its 5-HT4 receptor affinity by at least 150 times. Prucalopride is therefore differentiated from other 5-HT4 receptor agonists such as tegaserod and cisapride, whose affinity for other receptors/channels such as 5-HT1,2 (tegaserod) and the 5-HT2 and human Ether àgo-go Related Gene (hERG) channel (cisapride) is in the same range as their affinity for the 5-HT4 receptor. ${ }^{17}$

\section{CLINICAL PHARMACOLOGY}

Prucalopride has low plasma protein binding, with mean values ranging from $28.9 \%$ to $33.3 \%$. It is rapidly absorbed from the gastrointestinal tract when given orally. The bioavailability of the drug is high (>93\%) and is not altered by intake of food. The drug can be taken at any time of the day, however, in clinical practice it is usually suggested to take it early morning, as it supplements with the physiologic reflexes stimulating colonic motility. Once given orally, the maximum concentration is reached within 2-3 hours and its plasma terminal half-life is projected to be about $30 \mathrm{~h}$.

The steady state is achieved after 4-7 days of treatment, and plasma concentration directly increases by increasing the dose. Because of these characteristics prucalopride can reach the therapeutic effect rapidly, with the first spontaneous bowel movement expected after a median of 2.5 hours and the first spontaneous complete bowel movement within a median of 50-54 hours. ${ }^{18-19}$ Prucalopride is barely metabolized in humans: only small quantities of its metabolites can be found in urine and faeces, whereas $60 \%$ of the drug can be found unchanged in urine and $6 \%$ in faeces. Renal parameters of the 
individual determine renal clearance $(\mathrm{Cl}$ renal) and apparent total clearance of the drug: in subjects with mild renal impairment, the reduced clearance does not significantly alter the PK profile; however, in subjects with moderate and severe renal impairment, area under the plasma concentration-time curve from time zero

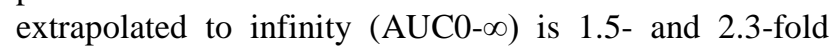
higher, and $\mathrm{t} 1 / 2$ is prolonged by about $40 \%$ and $50 \%$, respectively.

Findings from PD studies indicate that prucalopride decreases total colonic transit time and thereby increases motility of the colon in both healthy subjects and patients with CIC. An integrated analysis of 3 randomized, placebocontrolled, Phase 2 dose-finding studies in 280 patients with CIC showed a clear correlation between constipation symptom severity and increased colonic transit time, and that improvements in CIC response correlated with decreased colonic transit time. ${ }^{20-22}$

\section{DOSAGE, CLINICAL EFFICACY AND DRUG INTERACTIONS}

Three dose-response studies (PRU-INT-1, PRU-INT-2, and PRU-USA-3), supported the testing of $2 \mathrm{mg}$ and $4 \mathrm{mg}$ QD in the initial Phase 3 studies (Studies 6, USA-11, and USA-13). Results of these studies showed that the $4 \mathrm{mg}$ QD prucalopride dose provided no significant benefit over the $2 \mathrm{mg}$ QD dose. Therefore, a dose of $2 \mathrm{mg} \mathrm{QD}$ is considered appropriate for the treatment of CIC in adult patients. Only the $2 \mathrm{mg}$ QD dose was investigated in Studies 3001 and 302.

The $1 \mathrm{mg}$ dose is the recommended dose in patients with severe renal impairment (glomerular filtration rate less than $30 \mathrm{~mL} / \mathrm{min} / 1.73 \mathrm{~m} 2) .{ }^{23}$ As Prucalopride is not dependant on cytochrome P450 system metabolism, and minimally binds to plasma protein, the drug displays very low drug-drug interactions; thus, it is possible to administer prucalopride together with other laxatives featuring a different mechanism of action (e.g. osmotics, bulking agents, softeners, etc.)

\section{SAFETY AND ADVERSE DRUG REACTIONS}

The lack of selectivity of most serotonin receptor agonists developed in these recent years caused serious, especially cardiovascular, adverse events. ${ }^{24}$ However, prucalopride is a completely different serotonin receptor agonist, because its molecular structure (benzofurancarboxamide derivative) has high affinity for the human 5HT4 receptors. Its high selectivity may explain the relatively low number of adverse events reported after treatment.

Indeed, no significant hemodynamics or ECGs changes (in particular, no increase in the incidence of prolongation of the QTc interval) were found both in healthy controls and patients. ${ }^{25}$ In healthy subjects, heart rate (HR) increases of 5-8 bpm have been seen at 3 hours [Cmax] of first-time administration of prucalopride, however the same returned to baseline at steady state. No other cardiovascular effects have been noted in nonclinical species at concentrations of at least 50 times the therapeutic plasma concentrations in humans. Also, the drug has not shown any effect on coronary artery contraction or platelet aggregation at concentrations exceeding those seen with the therapeutic dose of $2 \mathrm{mg}$ once daily (QD). ${ }^{26}$ Due to concerns regarding possible cardiovascular risk in patients treated with nonselective 5-HT4 agonist products, Shire conducted extensive proactive and retrospective analyses on cardiovascular and major adverse cardiovascular events (MACE) risk. All investigations have been unable to demonstrate increased cardiovascular risk. ${ }^{27}$

Concerning adverse effects, there were 4 AEs reported with an incidence of $>5 \%$ : headache $(17 \%)$, nausea $(14 \%)$, diarrhea (12\%), and abdominal pain (10\%). These 4 AEs occurred at a higher rate in patients on prucalopride than placebo and were consistently reported among the 16 randomized controlled studies. (Table 2) However, adverse events were generally transient and lasted $<5$ days. The majority of these AEs were mild or moderate in severity. There was a low incidence of severe AEs, with only 2-3\% of patients reporting a severe headache, nausea, diarrhea, or abdominal pain over the entire course for each of the controlled studies. ${ }^{28,29}$

Table 2: Commonly Reported (>5\%) Adverse Events in Pooled Randomized Double-blind Placebo-controlled Studies $\geq 4$ Weeks.

\begin{tabular}{|lllll|}
\hline \multicolumn{1}{|c|}{$\begin{array}{l}\text { Placebo } \\
\text { N=1973 }\end{array}$} & $\begin{array}{l}\text { Prucalopride } \\
\text { Total }\end{array}$ & $\begin{array}{l}1 \mathrm{mg} \\
\mathrm{N}=3305\end{array}$ & $\begin{array}{l}\text { 2 m* } \\
\mathrm{N}=1516\end{array}$ \\
\hline Any AE & $1058(53.6 \%)$ & $2146(64.9 \%)$ & $184(55.8 \%)$ & $964(62.4 \%)$ \\
\hline Headache & $186(9.4 \%)$ & $642(19.4 \%)$ & $44(13.3 \%)$ & $265(17.5 \%)$ \\
\hline Nausea & $126(6.4 \%)$ & $509(15.4 \%)$ & $32(9.7 \%)$ & $206(13.6 \%)$ \\
\hline Diarrhoea & $72(3.6 \%)$ & $396(12.0 \%)$ & $27(8.2 \%)$ & $179(11.8 \%)$ \\
\hline Abdominal pain & $153(7.8 \%)$ & $321(9.7 \%)$ & $22(6.7 \%)$ & $151(10.0 \%)$ \\
\hline
\end{tabular}

Note: Randomized DBPC=16 Phase 2-4 studies $\geq 4$ weeks duration in chronic idiopathic constipation, * Includes all patients titrated from prucalopride $1 \mathrm{mg}$ to $2 \mathrm{mg}$. 


\section{CLINICAL TRIALS}

Prucalopride is a highly selective serotonin 5-HT4 receptor agonist which has been shown to stimulate gut motility in vitro and in vivo. ${ }^{30}$ Scintigraphic studies conducted in healthy volunteers have revealed that the drug accelerated whole gut and colonic transit, however it does not affect gastric emptying or small bowel transit. ${ }^{31}$ Among patients with constipation, nevertheless, the very same authors using the exact same scintigraphic technique found that prucalopride in doses of 2 or $4 \mathrm{mg}$ daily accelerated whole gut, gastric, small bowel and colonic transit in constipated patients. ${ }^{32}$ Importantly, prucalopride does not have any adverse effects on anorectal motor function or rectal sensation in either healthy volunteers or patients with constipation. ${ }^{32,33}$ In studies of colonic motility, prucalopride has been shown to be stimulatory. ${ }^{34,35}$

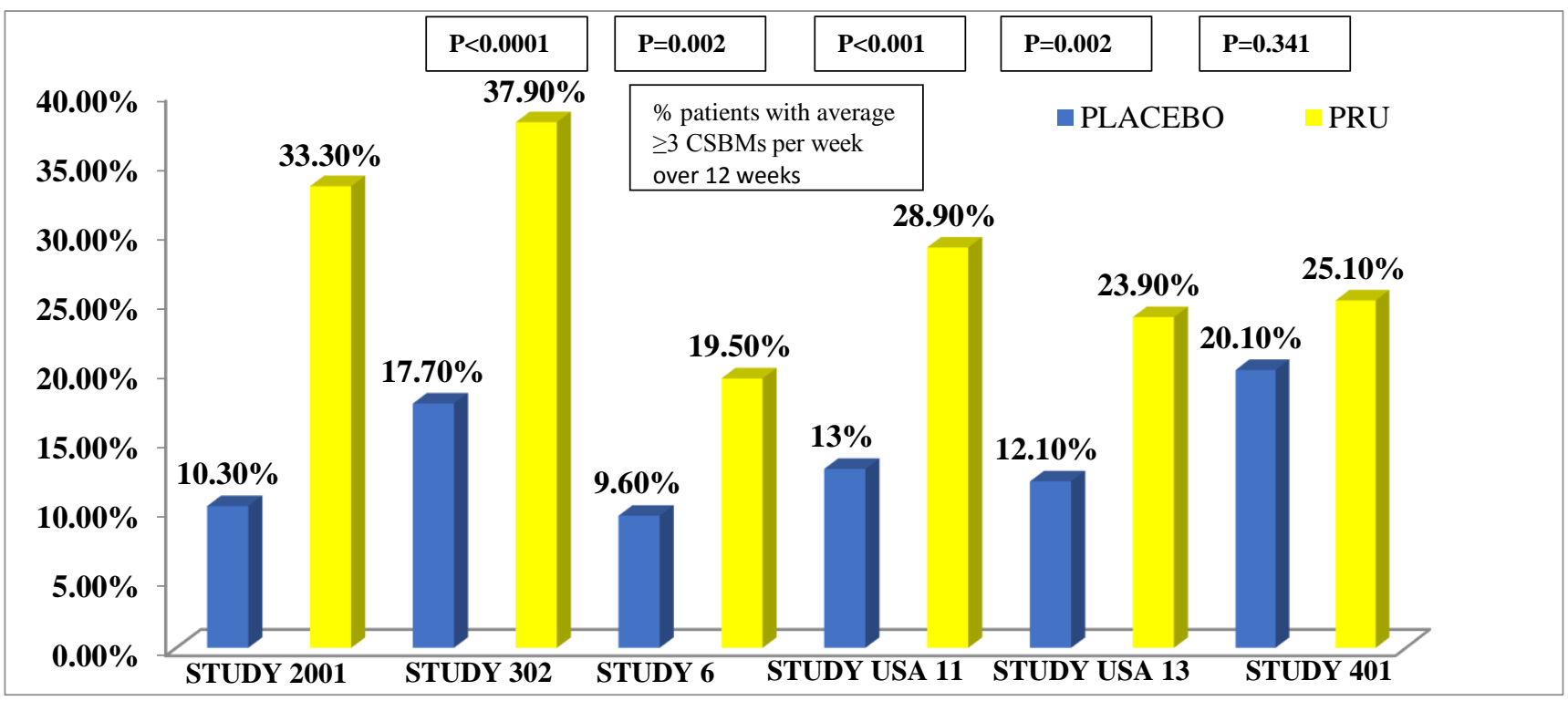

CSBM=complete spontaneous bowel movement; PRU=prucalopride

*Week 12 data presented

Figure 1: Primary Endpoint- Proportion of patients achieving $\geq 3$ CSBM's/week over weeks 1-12 in randomized double blind placebo controlled studies $\geq 12$ weeks. ${ }^{36}$

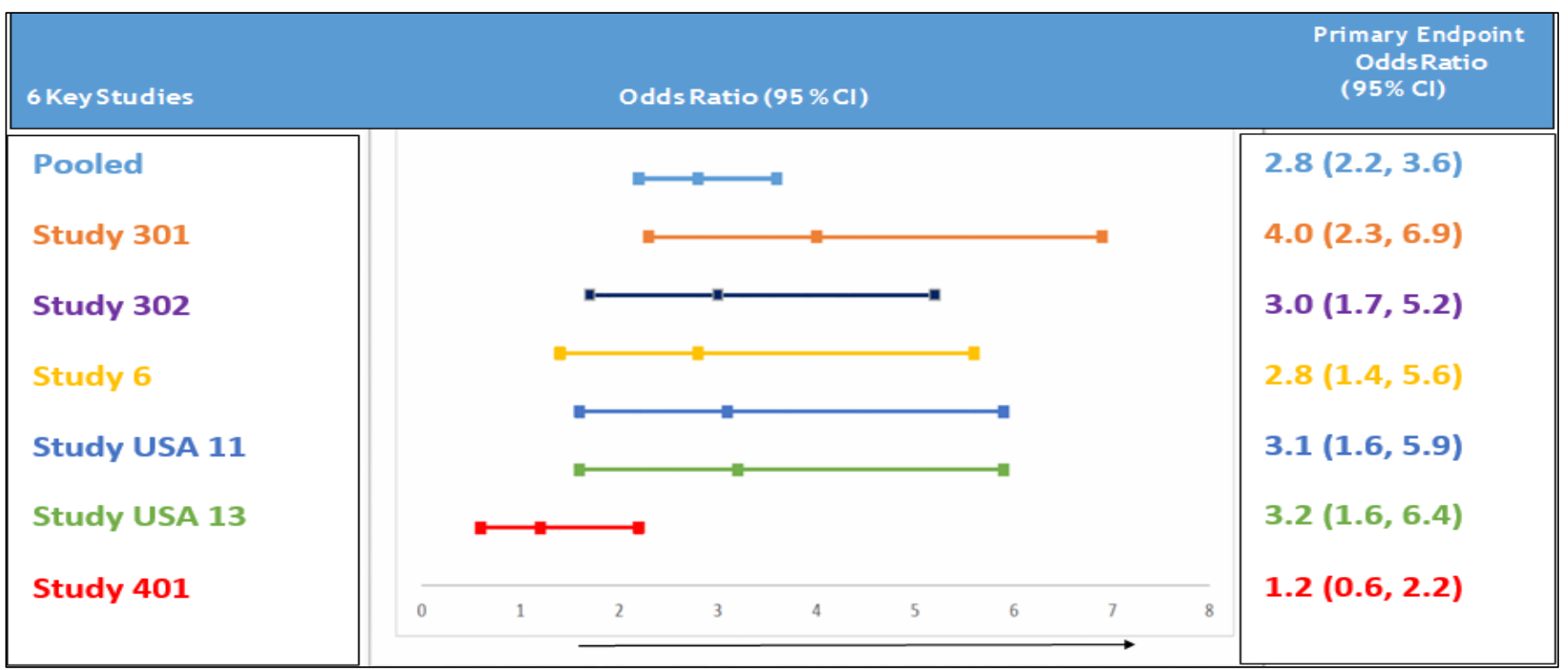

Favours Prucalopride, $\mathrm{CI}=$ confidence interval; OR=odds ratio

Figure 2: Forest Plot of Primary Efficacy Endpoint Results in Randomized Double blind Placebo-controlled Studies $\geq 12$ Weeks. $^{36}$ 
The evidence of efficacy of prucalopride comes from 6 randomized, double-blind, placebo-controlled studies of $\geq 12$ weeks duration in patients with confirmed CIC: Studies 3001, 302, 6, USA-11, USA-13, and 401. Patients were selected for the studies based on modified ROME Foundation diagnostic criteria for functional constipation. Exclusion criteria for the studies included patients with constipation caused by secondary causes (drug-induced or after surgery), organic disorders of the large bowel (megacolon/megarectum, pseudo-obstruction), those with comorbidities (uncontrolled cardiovascular, liver, or lung disease, neurologic or psychiatric disorders, cancer or acquired immune deficiency syndrome) and impaired renal function (creatine clearance $<30 / \leq 50 \mathrm{~mL} / \mathrm{min}$ ). Prucalopride $2 \mathrm{mg}$ and $4 \mathrm{mg}$ were included in the initial studies; however, the $4 \mathrm{mg}$ dose was omitted from the later studies due to lack of increased efficacy compared to the 2 mg dose. In Studies 302 and 401, patients $\geq 65$ years of age started at a dose of $1 \mathrm{mg}$ prucalopride QD, with the option to increase to $2 \mathrm{mg}$ QD.

If the dose was increased to $2 \mathrm{mg}$ QD, the patient remained on this dose for the duration of the study. Since the majority of patients who initially started on prucalopride 1 $\mathrm{mg}$ increased to $2 \mathrm{mg}$ during the study, the efficacy results for these studies were combined into a single group identified as $2 \mathrm{mg}$. Five of the 6 studies (3001, 302, 6, USA-11, and USA-13) met the primary endpoint, showing a higher proportion of patients treated with prucalopride achieving $\geq 3$ CSBMs per week over the 12-week treatment period (Figure 1,2). The absolute treatment effect between the arms was statistically significant in Studies 3001, 302, 6, USA-11, and USA-13 (p<0.01). Importantly, the effects of prucalopride on CSBMs/week occurred quickly and persisted. In the 5 positive efficacy studies with prucalopride, the response was attained within the first week and maintained over the entire treatment period. ${ }^{36}$

Prucalopride consistently showed numerically and/or statistically significantly better results compared with placebo on the secondary efficacy endpoints, including the proportion of patients with an average increase of $\geq 1$ CSBM, the increase in average number of CSBMs, the time to first CSBM, and improvement in PAC-SYM and PAC-QOL scores. Overall, prucalopride increased the frequency of bowel movements and improved symptoms and health-related quality of life in patients with CIC. ${ }^{36}$

\section{CONCLUSION, PLACE IN THERAPY}

As on date, prosecretory agents are the current first line treatment for chronic idiopathic constipation not responsive to other over-the-counter medications. In the current scenario, the restriction to laxative failures is also very much in keeping with a number of authoritative guidelines which suggest a step-up approach to the treatment of constipation: beginning with dietary and lifestyle changes, progressing through osmotic laxatives (such as polyethylene glycol derivatives) and reserving pharmacological therapies for people whose condition fails to respond to these steps. It must be stressed that there are very few studies comparing the efficacy of a new pharmacological agent with a traditional laxative; for this reason, the real therapeutic gain attributable to prucalopride over and above a laxative remains somewhat conjectural. In contrast, as seen in day to day practice, there is a large group of patients who either do not respond or tolerate or have contraindications to prosecretory agents. This has led to an inevitable requirement for discovering safe and effective CIC treatments.

Prucalopride is a highly selective serotonin 5-HT4 receptor agonist which acts as a prokinetic in the gut. Clinical trials for Prucalopride to date have been positive, and maiden results suggest that prucalopride may be a new safe and effective option for CIC treatment, especially for patient's refractory to or unable to tolerate prosecretory agents. As a prescription drug for the management of constipation and given the virtual demise of other prokinetic agents for this indication, prucalopride competes primarily with another class of agents: those that stimulate secretion.

To date, cardiac toxicity, which bedevilled other drugs in this class, has not been a major issue. Long-term studies and post marketing data will be critical in assessing the real benefits and risks of this promising compound.

Funding: No funding sources

Conflict of interest: None declared

Ethical approval: Not required

\section{REFERENCES}

1. Longstreth GF, Thompson WG, Chey WD, Houghton LA, Mearin F, Spiller RC. Functional bowel disorders. Gastroenterol. 2006Apr1;130(5):1480-91.

2. Belsey J, Greenfield S, Candy D, Geraint M. Systematic review: impact of constipation on quality of life in adults and children. Alimentary pharmacol \& therapeutics. 2010May;31(9):938-49.

3. Wald A, Scarpignato C, Kamm MA, Mueller-Lissner S, Helfrich I, Schuijt C, et al. The burden of constipation on quality of life: results of a multinational survey. Alimentary pharmacol \& therapeutics. 2007Jul1;26(2):227-36.

4. Cook IJ, Talley NJ, Benninga MA, Rao SS, Scott SM. Chronic constipation: overview and challenges. Neurogastroenterol and Motility. 2009Dec;21:1-8.

5. Camilleri M, Ford AC, Mawe GM, Dinning PG, Rao SS, Chey WD, et al. Chronic constipation. Nature reviews Disease primers. 2017Dec14;3:17095.

6. Suares NC, Ford AC. Prevalence of, and risk factors for, chronic idiopathic constipation in the community: systematic review and meta-analysis. The American J Gastroenterol. 2011Sep;106(9):1582.

7. Bosshard W, Dreher R, Schnegg JF, Büla CJ. The treatment of chronic constipation in elderly people. Drugs Aging. 2004Dec1;21(14):911-30. 
8. Higgins PD, Johanson JF. Epidemiology of constipation in North America: a systematic review. Am J Gastroenterol. 2004Apr;99(4):750.

9. Peppas G, Alexiou VG, Mourtzoukou E, Falagas ME. Epidemiology of constipation in Europe and Oceania: a systematic review. BMC gastroenterol. 2008 Dec;8(1):5.

10. Prather CM, Camilleri M, Zinsmeister AR, McKinzie S, Thomforde G. Tegaserod accelerates orocecal transit in patients with constipation-predominant irritable bowel syndrome. Gastroenterol. 2000Mar 1;118(3):463-8.

11. Loughlin J, Quinn S, Rivero E, Wong J, Huang J, Kralstein $J$ et al. Tegaserod and the risk of cardiovascular ischemic events: an observational cohort study. J cardiovascular pharmacol and therape. 2010Jun;15(2):151-7.

12. Tack J, Van Outryve M, Beyens G, Kerstens R, Vandeplassche L. Prucalopride (Resolor) in the treatment of severe chronic constipation in patients dissatisfied with laxatives. Gut. 2009Mar1;58(3):35765 .

13. Shin A, Camilleri M, Kolar G, Erwin P, West CP, Murad MH. Systematic review with meta-analysis: highly selective 5-HT4 agonists (prucalopride, velusetrag or naronapride) in chronic constipation. Aliment Pharmacol Ther. 2014,39:239-53.

14. Mawe GM, Hoffman JM. Serotonin signalling in the gut--functions, dysfunctions and therapeutic targets. Nat Rev Gastroenterol Hepatol. 2013,10:473-86.

15. Bassotti G, Chistolini F, Nzepa FS, Morelli A. Colonic propulsive impairment in intractable slow-transit constipation. Arch Surg. 2003,138:1302-4.

16. De Schryver AM, Andriesse GI, Samsom M, Smout AJ, Gooszen HG, Akkermans LM. The effects of the specific 5HT(4) receptor agonist, prucalopride, on colonic motility in healthy volunteers. Aliment Pharmacol Ther. 2002,16:603-12.

17. De Maeyer JH, Lefebvre RA, Schuurkes JA. 5-HT4 receptor agonists: similar but not the same. Neurogastroenterol Motil. 2008,20:99-112.

18. Van De Velde VJ, Ausma JJ, Vandeplassche LM. Kinetics and absolute oral bioavailability of prucalopride. Gastroenterol. 2010,138(5 Suppl 1):S230.

19. Tack J, Quigley E, Camilleri M, Vandeplassche L, Kerstens R. Efficacy and safety of oral prucalopride in women with chronic constipation in whom laxatives have failed: an integrated analysis. United European Gastroenterol J. 2013,1:48-59.

20. Bouras EP, Camilleri M, Burton DD, Thomforde G, McKinzie S, Zinsmeister AR. Prucalopride accelerates gastrointestinal and colonic transit in patients with constipation without a rectal evacuation disorder. Gastroenterol. 2001Feb1;120(2):354-60.

21. De Schryver AM, Andriesse GI, Samsom M, Smout AJ, Gooszen HG, Akkermans LM. The effects of the specific 5HT4 receptor agonist, prucalopride, on colonic motility in healthy volunteers. Alimentary pharmacol Ther. 2002Mar1;16(3):603-12.
22. Emmanuel A, Cools M, Vandeplassche L, Kerstens R. Prucalopride improves bowel function and colonic transit time in patients with chronic constipation: an integrated analysis. The American J gastroenterol. 2014Jun;109(6):887.

23. Diederen K, Mugie SM, Benninga MA. Efficacy and safety of prucalopride in adults and children with chronic constipation. Expert Opin. Pharmacother. 2015,16:407-416.

24. Stillman MJ, Tepper DE, Tepper SJ, Cho L. QT prolongation, Torsade de Pointes, myocardial ischemia from coronary vasospasm, and headache medications. Part 2:review of headache medications, drug-drug interactions, QTc prolongation, and other arrhythmias. Headache. 2013,53:217-24.

25. Mendzelevski B, Ausma J, Chanter DO, Robinson P, Kerstens R, Vandeplassche L, et al. Assessment of the cardiac safety of prucalopride in healthy volunteers: a randomized, double-blind, placebo- and positivecontrolled thorough QT study. Br J Clin Pharmacol. 2012,73:203-9.

26. Conlon K, De Maeyer JH, Bruce C, Schuurkes JA, Christie L, McRedmond J, et al. Nonclinical Cardiovascular Studies of Prucalopride, a Highly Selective 5-Hydroxytryptamine 4 Receptor Agonist. J Pharmacol Exper Ther. 2018 Feb1;364(2):156-69.

27. Gilsenan A, Fortuny J, Plana E, Ruigómez A, Karlsson P, Flynn RW, et al. 386-Non-interventional cohort study of the relative incidence of major cardiovascular events among patients initiating prucalopride versus a matched comparator cohort initiating polyethylene glycol 3350 (PEG). Gastroenterol. 2018May $1 ; 154(6):$ S-92.

28. Leelakusolvong S, Ke M, Zou D, Choi SC, Tack J, Quigley EM, et al. Factors predictive of treatmentemergent adverse events of prucalopride: an integrated analysis of four randomized, double-blind, placebocontrolled trials. Gut Liver. 2015,9:208-13.

29. Camilleri M, Beyens G, Kerstens R, Robinson P, Vandeplassche L. Safety assessment of prucalopride in elderly patients with constipation: a double-blind, placebo-controlled study. Neurogastroenterol Motil. 2009,21:1256-e117

30. Sanger GJ, Quigley EM. Constipation, IBS and the 5HT4 receptor: what role for prucalopride? Clinical Medicine. Gastroenterol. 2010Jan;3:CGast-S4136.

31. Bouras EP, Camilleri M, Burton DD, McKinzie S. Selective stimulation of colonic transit by the benzofuran 5HT4 agonist, prucalopride, in healthy humans. Gut. 1999May1;44(5):682-6.

32. Bouras EP, Camilleri M, Burton DD, Thomforde G, McKinzie S, Zinsmeister AR. Prucalopride accelerates gastrointestinal and colonic transit in patients with constipation without a rectal evacuation disorder. Gastroenterol. 2001Feb1;120(2):354-60.

33. Coremans G. Prucalopride: the evidence for its use in the treatment of chronic constipation. Core evidence. 2008Jun;3(1):45.

34. De Schryver AM, Andriesse GI, Samsom M, Smout AJ, Gooszen HG, Akkermans LM. The effects of the 
specific 5HT4 receptor agonist, prucalopride, on colonic motility in healthy volunteers. Alimentary Pharmacol Ther. 2002Mar1;16(3):603-12.

35. Quigley EM. Prucalopride: safety, efficacy and potential applications. Therapeutic advances in gastroenterol. 2012 Jan;5(1):23-30.

36. Camilleri M., Piessevaux H., Yiannakou Y., Tack J., Kerstens R., Quigley E, et al. Efficacy and Safety of Prucalopride in Chronic Constipation: An Integrated
Analysis of Six Randomized, Controlled Clinical Trials. Dig Dis Sci. 2016;61:2357-72.

Cite this article as: Dhull $\mathrm{P}$, Maggo S, Angrish $\mathrm{P}$, Singh A, Uthara KS, Akhila AS. Prucalopride- Novel drug for chronic idiopathic constipation. Int J Basic Clin Pharmacol 2019;8:1923-9. 